\title{
Introduction to the special issue on electronic government: investment in communities, firms, technologies and infrastructure
}

\author{
Christopher L. Tucci ${ }^{1}$ - Diane Poulin ${ }^{2}$
}

Published online: 23 July 2015

(C) Springer Science+Business Media New York 2015

We are pleased to introduce this special issue of ECR addressing new developments in e-government. Despite the differences in governing political regions and that of managing industry and commerce, there are many similarities that are shared when these endeavors are implemented on electronic platforms. E-government allows information technology to proactively strengthen governmental efficiency through enhanced communication and coordination of-among other stakeholders-citizens, businesses and the agencies that provide governmental services. The U.S. Government Accountability Office and the OECD both suggest that e-government research should be directed toward applying information and communication technologies (ICTs) with the goals of lowering costs concurrent with the strengthening of democracy and participation in civil society. To that end, we have included seven research papers in this special issue. Our first paper, Shaping public sector innovation theory, proposes an innovative model for ICT-enabled governance and policy, with an emphasis on public-sector innovation. Our second paper, on Web 2.0 technologies and their implications for local governance, explores how these technologies may change the role of local governments and their interactions with citizen stakeholders. Our third paper, Crowdsourcing as a tool for e-participation provides an assessment of tools to tap into grassroots knowledge in

Christopher L. Tucci

christopher.tucci@epfl.ch

Diane Poulin

diane.poulin@fsa.ulaval.ca

1 College of Management, Ecole Polytechnique Fédérale de Lausanne (EPFL), Odyssea 1.04, Station 5, 1015 Lausanne, Switzerland

2 Department of Management, Faculty of Business Administration, Université Laval, 2325 rue de la Terrasse, Quebec City, QC G1V 0A6, Canada 
search of solutions to municipal problems. Following this is Factors influencing e-government use in non-urban areas, which extends our understanding of the factors influencing the attitudes of non-urban residents toward e-government. Next, Analog Citizens, addressing the "digital divide" and its effect on three groups: seniors; dropouts/homeless living in cities; and Native Americans (First Nation) living in remote communities. Our next paper, Legal Aspects of Accessibility and Usability of Online Public Services in Quebec and Canada, discusses the delivery of public online services to individuals with a low literacy level. Our final paper, Key E-Government Issues in China, explores the current state of e-government in rapidly developing China.

We hope our readers find these articles stimulating as they expand the combined discourse on e-commerce and e-government. And we enthusiastically look forward to further research in this exciting but under-explored area! 